\title{
В.Д. Филимонов
}

\section{ВОПЛОЩЕНИЕ ГЕНЕЗИСА ПРЕСТУПЛЕНИЯ В ПРАВОВОМ СОДЕРЖАНИИ СОСТАВА ПРЕСТУПЛЕНИЯ}

\begin{abstract}
Рассматривается воплощение генезиса преступления в правовом содержании состава преступления. Формулируется итоговый вывод, что с точки зрения системного подхода к исследованию явлений, состав преступления представляет собой классическую систему, элементы которой и связи, объединяющие их между собой и с элементами смежных систем, формируют качественное своеобразие изучаемого явления.
\end{abstract}

Ключевые слова: генезис преступления, состав преступления, признаки преступления, признаки состава преступления.

Преступление может рассматриваться как событие в общественной жизни и как общественно опасное деяние.

Как событие преступление включает в свое содержание наряду с деянием его объект, субъект и последствия деяния.

Как деяние оно включает в свое содержание только действие и бездействие, состоящее из объективных и субъективных элементов. Такое понимание соответствует закрепленному в ст. 14 УК РФ законодательному определению преступления.

Действие и бездействие как процесс воздействия человека на объект преступления, выражающийся в самом причинении ему вреда или в иных видах его детерминации, появляются в общественной жизни в начальный момент действия, а при бездействии - в момент возникновения у лица обязанности действовать. В одном из этих двух случаев имеет место причинная связь между деянием человека и его последствиями, а во втором случае - как правило, кондициональная связь между ними. В некоторых видах общественно опасного поведения возможны и другие виды детерминации преступления с его общественно опасными последствиями - функциональная, инспирирующая, системная и т.п. Все они так же, как и причинная связь, могут рассматриваться в качестве составных частей состава преступления как основания возложения уголовной ответственности.

Так, например, при убийстве обычно обнаруживается причинная связь между действием виновного и смертью потерпевшего, а при отказе от помощи больному (бездействии врача) - кондициональная связь между поведением человека и возникшей опасностью для жизни и здоровья человека. При совиновничестве в преступлении можно констатировать и более сложную детерминацию преступных последствий: действия совиновников (в том числе и в составе преступной группы) объединены между собой функциональной взаимозависимостью, а затем как единое целое - причинной связью с последствиями преступления.

Все это необходимо иметь в виду при выявлении генезисов различных видов преступного поведения. Так, если опасность для жизни или здоровья больного возникла в результате преступных действий какого- либо человека, то у его поведения и поведения лица, отказавшегося от помощи больному, разные генезисы преступления.

Разные генезисы преступного поведения в результате неодинаковой природы детерминирующих связей деяния и его последствий порой можно обнаружить также при сравнении мотивов поведения у подстрекателя и исполнителя преступления. Например, мотивом подстрекательства к убийству может быть месть потерпевшему (инспирирующая связь), мотивом же действий исполнителя преступления - ревность (причинная связь).

Для наиболее полного представления об обусловленности генезисом общественно опасного деяния признаков состава преступления приходится вновь вернуться к особенностям их социальной и правовой природы. При этом необходимо обратить внимание на то, что состав преступления по своему содержанию шире, чем совокупность признаков, присущих общественно опасному деянию.

Состав, как закрепленная в законе правовая конструкция, включает в свое содержание не только признаки, имманентно присущие преступлению (объективные и субъективные признаки самого деяния), но и такие признаки, которые лишь характеризуют общественную опасность деяния. К ним помимо признаков, имманентно присущих самому деянию, относятся прежде всего признаки объекта и субъекта преступления - обязательные признаки состава преступления, а также формирующаяся в процессе совершения деяния непосредственная опасность причинения вреда объекту преступления. Его материальные последствия, а также некоторые другие обстоятельства совершения преступления (например, обстановка) относятся к числу факультативных признаков состава.

Преступное деяние всегда обладает общественной опасностью. Включая в свое содержание мотив, форму вины и цель воздействия на общественные отношения, выражающие антиобщественные свойства сознания человека, оно во всех случаях придает его действию или бездействию антиобщественную направленность.

В отличие от признаков самого деяния, иные признаки, формирующие состав преступления, имеют релятивный, то есть относительный характер. 
Объектом преступления являются, как известно, охраняемые уголовным правом общественные отношения. Они представляют собой важнейшую социальную ценность и уже по этой причине не могут считаться составной частью преступления. Но они способны характеризовать деяние, причиняющее им ущерб. Только в этом отношении они и могут включаться в состав преступления.

Возраст и вменяемость человека также не содержат в себе никакой общественной опасности. Этими признаками обладают и законопослушные граждане. Элементами состава преступления они становятся потому, что характеризуют способность человека осознавать общественную опасность совершаемого деяния и руководить своим поведением. Другими словами, они включаются в состав преступления потому, что являются обязательными критериями существования вины, без которой преступное поведение невозможно.

Материальные последствия деяния тоже обладают относительным характером. Способность характеризовать общественную опасность деяния они приобретают только в связке с антиобщественным содержанием мотива, формы вины и цели преступления. Это их свойство обусловливается и некоторыми другими обстоятельствами совершения действия или бездействия. Например, причинение смерти человеку может расцениваться в одних случаях как убийство, а в других - как причинение смерти в состоянии необходимой обороны.

При выявлении роли генезиса преступления при решении вопроса о закреплении в составе преступления последствий преступления необходимо иметь в виду, что без общественно опасных последствий, как уже неоднократно отмечалось в юридической литературе, преступлений не бывает [1, с. 171].

Если бы деяние не вызывало общественно опасных последствий, не было бы оснований признавать его преступлением. Противники этой точки зрения не учитывают того, что в одних случаях последствия преступления выражаются в создании самой непосредственной опасности причинения вреда общественным отношениям, а в других - в причинении им материального ущерба.

Опасность причинения вреда общественным отношениям - это обязательный, имманентно присущий общественно опасному деянию признак преступления. Он по нарастающей степени в течение всего времени его совершения сопровождает сам процесс причинения вреда объекту преступления. Главным образом именно по этой причине преступное деяние рассматривается законодателем в теории уголовного права как деяние общественно опасное, то есть создающее угрозу причинения вреда, а не причинившее вред.

Таким образом, можно сделать вывод, что при анализе социального содержания любого состава преступления последствия, которые наступают в результате его совершения, всегда должны рассматриваться как обязательные признаки, характеризующие его общественную опасность. При анализе же состава преступления как правовой конструкции они в число самостоятельных его признаков входят далеко не всегда. В этом последнем случае они оказываются представлен- ными в составе преступления как свойства, имманентно присущие самому общественно опасному деянию.

Факультативные признаки преступления рассматриваются в качестве таковых потому, что не всегда включаются в составы преступлений. Однако в тех случаях, когда эти признаки становятся признаками соответствующего состава преступления, они приобретают обязательный характер.

В одних случаях они как элементы состава преступления действительно не являются обязательными. Например, некоторые средства совершения общественно опасного деяния, в частности ножи, топоры, охотничьи ружья и т.П., постоянно используются людьми для хозяйственных и иных нужд, а не только для совершения преступления. Поэтому в состав убийства они не включаются. Даже обстановка совершения преступления, повышающая степень его общественной опасности, не всегда может считаться признаком состава преступления. Все зависит от характера поведения человека. Например, условия общественного бедствия, усиливающие ответственность за совершение некоторых видов преступного поведения, способны при оценке других поступков сыграть прямо противоположную роль. Так, при оказании помощи гибнущим людям они могут стать основанием признания некоторых поступков спасателей героическими.

В других случаях факультативные признаки состава являются показателями большого объема нанесенного преступлением вреда и (или) более высокой степени опасности содержащихся в субъективных признаках деяния антиобщественных свойств личности преступника (например, при убийстве, совершенном с особой жестокостью или совершенном общеопасным способом).

В юридической литературе анализ составов преступлений обычно начинают с характеристики их объективных признаков - объекта и признаков объективной стороны преступлений. Такой подход к изучению явлений не вызывает возражений. Он соответствует диалектикоматериалистическому методу их познания, согласно которому материя первична, а сознание вторично. Но метод познания явления по своей последовательности не всегда совпадает с последовательностью его действительного развития. С таким случаем приходится сталкиваться при анализе состава преступления.

Общественно опасное деяние, признаки которого состав отражает в норме уголовного права, свое существование начинает не в объективной действительности, а в сознании человека. Его истоками являются сформировавшиеся в нем антиобщественные свойства. В одних случаях они порождают невнимательное отношение к интересам иных лиц, общества или государства, в других становятся непосредственной субъективной причиной возникновения антиобщественного по своему содержанию мотива поведения, формы умысли и цели его осуществления.

Однако упрощать этот процесс не следует. В процессе формирования преступного намерения лицо не может не сознавать социальной значимости своих будущих действий. Она же во многом зависит не только от социальной оценки непреступного поведения, но от социальной оценки других видов преступлений. 
Так, например, одни и те же мотивы преступных деяний, даже посягающих на один и тот же объект преступления, могут в зависимости от объективных признаков преступного деяния иметь разную социальную трактовку. Можно сослаться, в частности, на разную социальную оценку корыстных мотивов при совершении хищении чужого имущества и при причинении ущерба собственности путем обмана и злоупотребления доверием (ст. 165 УК РФ).

Мотив и цель преступления - родственные явления. Иногда их понятия используются в законе как во многом сходные: в одних случаях, например, речь идет о корыстных мотивах, в других - о корыстной цели преступления. Обычно закрепление их в составе преступления связано со стремлением законодателя указать в одних случаях на непосредственный нравственнопсихологический источник конкретного вида преступного поведения (мотив преступления), в других - на запланированный результат общественно опасного деяния (цель). Указание на нравственно-психологический источник совершения преступления характеризует меру противопоставления личных интересов общественным интересам и общественную опасность совершенного преступления. Указание же на цель преступления (например, при убийстве цель скрыть преступление или облегчить его совершение) используется законодателем не только для того, чтобы выразить в преступлении указанную меру противопоставления, но и придать уголовно-правовое значение направленности поведения человека на достижение определенного результата, выразить его повышенную динамику.

Не каждую умышленную преступную деятельность можно признать мотивированной. При косвенном умысле, для которого характерно безразличное отношение виновного к преступным последствиям, мотива преступления обычно нет.

Нет его и в том случае, когда косвенный умысел на наступление тех или иных последствий соединяется с целенаправленной деятельностью на причинение иных последствий. Безразличное отношение к самому преступному результату в этих случаях можно считать мотивированным антиобщественными свойствами личности не всегда. Например, при спасении близкого человека, соединенном с безразличным отношением к окружающим людям.

Противопоставление личных интересов общественным возможно не только в виде целенаправленного нарушения интересов других лиц, общества или государства, но и в виде их игнорирования. Безразличное отношение к окружающим людям в таких случаях является следствием именно такого его проявления.

Мотив преступления может быть простым и сложным. Простым его можно считать тогда, когда он оказывается единственным, как, например, при карманных или квартирных кражах. Сложным его следует признать в тех случаях, когда он объединяет два и более мотивов совершения одного и того же преступления. Примером такого объединения может быть параллельная мотивация должностного злоупотребления как корыстными побуждениями, так и карьеристской заинтересованностью (стремлением получить более высо- кооплачиваемую работу и одновременно занять престижную должность).

В некоторых случаях совершение преступления оказывается детерминированным двумя и более мотивами, возникающими один за другим и связанными между собой. Однако необходимо учитывать, что уголовно-правовое значение имеют не все они. Так, если у человека возникло намерение совершить поездку заграницу для ознакомления с культурными ценностями другой страны и для получения средств на эту поездку - совершить хищение чужого имущества, то, несмотря на доминирующую роль в мотивации принятого решения мотивов духовного содержания, нести ответственность он будет все-таки за корыстное преступление. Мотив поведения приобретает уголовно-правовое значение только в обязательной связке с объектом преступления. Туристическая поездка никакого ущерба охраняемым уголовным правом общественным отношениям не наносит. Объекта преступления в этом случае нет. Следовательно, нет и мотива преступного поведения.

По своему социальному содержанию мотив представляет собой субъективную причину совершения преступления. Это обычно развивающееся явление, которое сначала формируется и закрепляется в сознании человека, конкретизируется в определенной программе его поведения, а затем переходит в стадию реализации. Реализация мотива - субъективно-объективный процесс: обусловленный потребностью человека и ее энергетическим потенциалом мотив становится источником одновременно как мыслительной деятельности человека (формированием и конкретизацией умысла и цели в процессе совершения преступления), так и производимых им изменений во внешней среде.

Антисоциальное содержание мотива преступления может быть различным [2-4]. Он может выражать корысть, личную неприязнь (мотивы мести, зависти, ревности), проявляться в социальной, национальной и религиозной вражде и т.п. Мотив может быть устойчивым и ситуативным. Во всех этих случаях он является показателем характера и степени общественной опасности обусловленного им поведения человека.

Сущность антисоциального содержания мотива преступления определяется тем, что он является одной из сторон противопоставления человеком своих эгоистических интересов общественным интересам.

Своим содержанием он прежде всего отвечает на вопрос - во имя чего совершается общественно опасное действие или бездействие. Другой стороной указанного противопоставления является отраженный в мотиве ущерб, причиняемый преступлением общественным интересам. Он отвечает на вопрос, что приносится в жертву ради удовлетворения преступником своих потребностей и интересов?

При этом при оценке меры противопоставления личных интересов общественным интересам во внимание принимаются не только характер и размер вреда, нанесенного преступником тому или иному виду охраняемым уголовным правом общественным отношениям, и их социальная ценность, но и интенсивность его причинения. 
Интенсивность преступления определяется, в частности, тем, совершается ли преступление путем действия или бездействия, а также видом детерминирующей обусловленности преступных последствий (причинной, кондициональной или иной связью с совершенным деянием).

Все указанные обстоятельства участвуют в формировании мотива преступления. Без них трудно представить в полном объеме заключенную в мотиве меру противопоставления личных интересов общественным интересам.

Противопоставление лицом своих эгоистических интересов общественным интересам находит выражение не только в субъективных, но и в объективных признаках совершенного им деяния. Они в совокупности определяют характер и степень общественной опасности преступления, а следовательно, и меру противопоставления личных интересов лица, совершающего преступление, интересам других лиц, общества или государства. По этой причине они и закрепляются в составе преступления.

Обусловленность признаков объективной стороны преступления проявленной лицом мерой противопоставления личных интересов общественным интересам можно обнаружить при анализе общественно опасного деяния как объективного признака преступления, а также способа совершения преступления и его последствий.

Общественно опасное деяние, как объективный элемент преступления, часто является не одноактным поступком, а представляет собой в разной степени продолжительный процесс причинения вреда объекту посягательства. Вследствие этого обстоятельства общественная опасность преступного деяния также становится развивающимся явлением.

По мере реализации преступного намерения она нарастает. Если достаточных условий для совершения преступления нет, то они создаются самим преступником - совершается приготовление к совершению преступления, которое, как стадия задуманного преступного поведения, само становится преступным деянием. Затем совершается непосредственное посягательство на охраняемые уголовным правом общественные отношения. Завершается преступление причинением вреда этим общественным отношениям. Таким образом, по мере реализации преступного намерения общественная опасность преступления все время нарастает. Пик этого нарастания приходится на момент причинения вреда объекту преступления в полном объеме. Все эти обстоятельства характеризуют постоянно возрастающую степень противопоставления личных интересов общественным интересам и в конечном итоге именно по этой причине становятся во многих случаях основаниями для закрепления в составе преступления соответствующих им признаков.

Способ совершения преступления представляет собой внешнее выражение того механизма преступного поведения, который, как правило, еще до его совершения сформировался в сознании человека. Он является неотъемлемым признаком преступных действий при любом умышленном преступлении. Если не считать пассивное поведение способом реализации некоторых программ общественно опасного поведения, то его нет и при преступном бездействии. Его наличия нельзя усмотреть и в случаях неосторожного совершения преступления. При неосторожной форме вины обычно приходится иметь дело не со способом совершения преступлении, а с ошибкой, допущенной в процессе реализации способа совершения правомерных или легкомысленных поступков.

В учебниках по общей части уголовного права способ традиционно рассматривается в качестве факультативного признака состава преступления. Но даже с учетом упомянутых только что случаев, способ является элементом состава не только тогда, когда он прямо описан в законе. Очень часто наименование самого действия содержит в себе указание на способ совершения преступления. Обычно это бывает тогда, когда существует много конкретных выражений такого способа и они по степени общественной опасности мало отличаются друг от друга. Убийство, например, может быть совершено путем использования холодного и огнестрельного оружия, ядов, удушения и т.П., но специально способ его совершения указывается в законе, как следует из содержания ст. 105 УК РФ, тогда, когда его использование приводит к причинению вреда дополнительному объекту преступления.

Способ совершения преступления включается в число признаков его состава еще и тогда, когда он, выражая более высокую вероятность и эффективность причинения вреда объекту преступления, значительно повышает общественную опасность совершенного действия.

Основания включения в состав преступления способа его совершения во всех таких случаях объясняются тем, что они имеют прямую связь с генезисом преступления. При указанных обстоятельствах генезис преступления путем указания на способ его совершения участвует в формировании меры противопоставления лицом своих личных интересов общественным интересам. В то же время следует признать, что указание в законе на способ совершения преступления не всегда имеет прямую связь с генезисом преступления. Так, например, в действующем УК РФ помимо общего состава мошенничества, предусмотренного в ст. 159, закреплены составы мошенничества в различных сферах имущественных отношений с детализацией способов их совершения (ст. ст. 159.1-159.6). Санкции этих статей, за исключением утратившей силу по постановлению Конституционного Суда Российской Федерации ст. 159.4, законодатель уравнял, что является показателем признания им равной степени общественной опасности предусмотренных в них преступлений, в том числе и с учетом одинаковых квалифицирующих их обстоятельств. Законодатель в этих случаях не увидел различий в степени противопоставления личных интересов общественным интересам. Дифференциация составов мошенничества в зависимости от способов его совершения потребовалась законодателю, скорее всего, для того, чтобы правоприменительные органы смогли избежать многочисленных ошибок при анализе большого числа различных правовых требований в различных сферах финансовой деятельности. 
Последствия преступления выражаются главным образом в изменениях в системе общественных отношений, наступивших в результате совершения преступления.

Система общественных отношений состоит из разных по своему содержанию и размеру звеньев. По содержанию общественные отношения могут быть подразделены на группы, которые выделены в Особенной части уголовного законодательства в качестве родовых объектов преступлений. Затем они делятся по видовым и непосредственным объектам преступлений. По своему объему общественные отношения могут быть представлены в виде общей совокупности охраняемых уголовным правом общественных отношений и в виде менее крупных социальных образований. На самом меньшем по своему объему уровне они предстают в виде общественных отношений, связывающих между собой отдельных лиц.

В связи с тем, что простейшее общественное отношение состоит из его субъектов, предмета (социального блага) и взаимосвязанных между собой потребностей субъектов относительно его предмета, объектом воздействия в результате совершения преступления может быть любая составная часть общественного отношения. При убийстве объектом воздействия становится субъект общественного отношения, при уничтожении имущества - его предмет, при краже - владение, пользование и распоряжение имуществом как функции его собственника.

В тех случаях, когда общественные отношения облечены в правовую форму и наделены статусом правовых отношений, объектами преступного воздействия становятся не только элементы общественных отношений, но и правовые формы их выражения. Так, преступление в сфере финансовых отношений может выражаться в воздействии на связи участников кредитных отношений в виде подделки документов или носителей компьютерной информации.

В результате совершения преступления общественные отношения, оказавшиеся объектом преступного посягательства, не просто нарушаются, а преобразуются. Преступник не просто нарушает общественные отношения, но и, преобразуя их, получает выгоду или иное удовлетворение от его совершения.

Прежние общественные отношения прекращают свое существование и замещаются новыми общественными отношениями. Если до совершения преступления они воплощали в своем содержании единство интересов большинства населения страны, общества и государства, то после его совершения они, изменяя свое содержание, становятся выразителями интересов лица, виновного в его совершении. Социальная справедливость во вновь возникших отношениях оказывается замененной социальной несправедливостью. При этом противопоставление личных интересов интересам других лиц, общества или государства получает воплощение в объективной действительности.

Все это, как и изложенное выше о социальном содержании последствия преступления, говорит о том, что оно является одним из основных показателей степени противопоставления личных интересов обще- ственным интересам, прямой связи последствия с генезисом преступления. На этом основании последствие преступления закрепляется в составе преступления в качестве его обязательного признака.

В формировании заключенной в преступном поведении меры противопоставления личных интересов общественным интересам участвуют причинная и виновная связи преступного деяния с его последствиями.

Причинная и виновная связи находят отражение в составе преступления как связи, в одном случае, преступного деяния с последствиями преступления, а в другом случае - субъекта преступления, а затем мотива как субъективного элемента преступного деяния, с теми же последствиями.

Но этой функцией роль причинной и виновной связи в возникновении общественно опасных последствий не ограничивается. Та и другая связь выступают в роли передатчика генезиса преступления от субъекта преступления, а затем и от преступного деяния тем преобразованиям, которые происходят в системе общественных отношений в результате его совершения.

По этой причине та и другая связь в процессе совершения преступления увеличивают степень общественной опасности преступного деяния.

Причинная связь в своем развитии постоянно повышает вероятность причинения вреда объекту преступления, а виновная связь в тех случаях, когда сознание лица, совершающего преступление, включает в свое содержание обстоятельства, увеличивающие степень его общественной опасности, повышает одновременно и степень вины преступника.

Все это отражается на содержании преступных последствий, которые, как и преступление, объединяют в своем составе как объективные, так и субъективные явления, - в данном случае объективные и субъективные элементы возникших в результате совершения преступления новых общественных отношений. Генезис преступления и содержащееся в нем противопоставление личных интересов общественным интересам через причинную и виновную связь преступного деяния с преступными последствиями не только передается их содержанию, но и по мере осуществления преступной деятельности наращивает в них свой объем.

Элементы преступного деяния, связи между ними и с причиняемыми преступлением преступными последствиями, воплощая в своем содержании генезис преступления, включаются законодателем в состав преступления. В состав преступления включаются также обстоятельства, характеризующие преступное деяние (объект преступления, его последствия, обстановка совершения преступления и некоторые свойства личности преступника). Но состав преступления во всех случаях это не просто совокупность его признаков, а такая совокупность, которая под воздействием формирующего его генезиса преступления образует единое целое.

С точки зрения системного подхода к исследованию явлений состав преступления представляет собой классическую систему, элементы которой и связи, объединяющие их между собой и с элементами смежных систем, формируют качественное своеобразие изучаемого явления. В состав преступления входят такие 
элементы и детерминирующие связи, в процессе взаимодействия которых между собой и с окружающей средой формируется общественная опасность преступления. Общественная опасность в этом случае определяется не совокупностью общественной опасности отдельных признаков деяния и внешних обстоятельств, которые их характеризуют, а их единством.

К этому выводу пришел и китайский специалист в области теории уголовного права Лун Чанхай [5]. Он обратил внимание на то, что если русские дореволюци- онные ученые под влиянием диалектики Гегеля рассматривали состав преступления как совокупность объективных и субъективных признаков, то советские правоведы под влиянием материалистической диалектики трактовали состав преступления как единство объективных и субъективных признаков. Именно единство признаков состава преступления позволяет ему стать выразителем генезиса конкретного преступления, то есть заключенной в нем меры противопоставления личных интересов общественным интересам.

\section{ЛИТЕРАТУРА}

1. Трайнин А.Н. Общее учение о составе преступления. М. : Госюриздат, 1957. 364 с.

2. Ковалев В.И. Мотивы поведения и деятельности. М. : Наука, 1988. 192 с.

3. Лунеев В.В. Мотивация преступного поведения. М. : Наука, 1991. 382 с.

4. Иванов Н.Г. Мотив преступного деяния : учеб. пособие. М. : Метод центр, 1997. 63 с.

5. Чанхай Лун. Учение о составе преступления по уголовному праву КНР и России: сравнительно-правовое исследование. Владивосток : Изд-во Дальневост. ун-та, 2010. 196 с.

\section{THE GENESIS OF CRIME IN THE LEGAL CONTENT OF CORPUS DELICTI}

Ugolovnaya yustitsiya - Russian Journal of Criminal Law, 2018, no. 12, pp. 40-45. DOI 10.17223/23088451/12/8

Vadim D. Filimonov, Tomsk State University (Tomsk, Russian Federation). E-mail: crim.just@mail.ru

Keywords: genesis of crime, corpus delicti, elements of crime, elements of corpus delicti.

Crime can be considered as an event in public life and as a socially dangerous act. As an event, a crime includes the act, its object, subject, and consequences. As an act, it includes only action and inaction, consisting of objective and subjective elements. This understanding corresponds to the legislative definition of crime in Article 14 of the Criminal Code. The commission of a crime leads to the situation when public relations, which have become the object of criminal encroachment, are not only violated, but also transformed. The offender not only violates social relations, but also, by transforming them, receives the benefit or other satisfaction from its commission. Former social relations cease to exist and are replaced by new social relations. If, before committing a crime, they embodied the unity of interests of the majority of the country population, society and the state, then after a crime was committed, they, by changing their content, express the interests of the person guilty of its commission. Social justice in the newly formed relations is replaced by social injustice. At the same time, the opposition of personal interests to the interests of other persons, society or the state is embodied in objective reality. All this affects on the content of criminal consequences, which, like a crime, combine in their structure both objective and subjective phenomena - the objective and subjective elements of the new social relations resulting from the commission of the crime. The genesis of a crime and personal interests opposed to public interests through the causal and guilty connection of a criminal act with criminal consequences affect not only its content, but also its scope. The author concludes that, from the point of view of a systematic approach to the study of phenomena, corpus delicti is a classical system, which has links between its elements and connecting its elements with adjacent systems. These links form a qualitative originality of the phenomenon under analysis. Corpus delicti includes such elements and links, the interaction of which with each other and with the environment determines the public danger of a crime. The public danger in this case is determined not by the combination of the public danger of individual elements of the act and their external circumstances, but by their unity.

\section{References}

1. Traynin, A.N. (1957) Obshchee uchenie o sostave prestupleniya [General Theory of Crime]. Moscow: Gosyurizdat.

2. Kovalev, V.I. (1988) Motivy povedeniya i deyatel'nosti [Motives of Behaviour and Activity]. Moscow: Nauka.

3. Luneev, V.V. (1991) Motivatsiya prestupnogo povedeniya [Motivation for Criminal Behaviour]. Moscow: Nauka.

4. Ivanov, N.G. (1997) Motiv prestupnogo deyaniya [The Motive of a Criminal Act]. Moscow: Metod tsentr.

5. Changhai Lun. (2010) Uchenie o sostave prestupleniya po ugolovnomu pravu KNR i Rossii: sravnitel'no-pravovoe issledovanie [The doctrine of corpus delicti in the criminal law of the PRC and Russia: A comparative legal study]. Vladivostok: Far Eastern Federal University. 